\title{
Helicobacter pylori infection coexisting with intestinal metaplasia is not associated with colorectal neoplasms
}

\author{
Banu Boyuk ${ }^{1}$, Arif Ozgur ${ }^{1}$, Hande Atalay², Aslan Celebi ${ }^{1}$, Ismail Ekizoglu¹, Engin Aykurt ${ }^{3}$ \\ ${ }^{1}$ Department of Internal Medicine, Istanbul Taksim Education and Research Hospital, Istanbul, Turkey \\ ${ }^{2}$ Department of Internal Medicine, Fatih Sultan Mehmet Education and Research Hospital, Istanbul, Turkey \\ ${ }^{3}$ Department of Nursing, Istanbul Taksim Education and Research Hospital, Istanbul, Turkey
}

Key words: Helicobacter pylori, colorectal neoplasia, intestinal metaplasia.

Address for correspondence: Hande Atalay MD, Department of Internal Medicine, Fatih Sultan Mehmet Education and Research Hospital, Istanbul, Turkey, phone: +90 53662986 69, e-mail: handeerman@yahoo.com

\begin{abstract}
Introduction: Colorectal cancer is one of the most common cancers and is a major cause of morbidity and mortality in the world and our country. Studies have indicated that there might be a relationship between Helicobacter pylori (Hp) and colorectal neoplasia (CN), although others have not found any relationship.

Aim: To determine whether there is a potential relationship between $\mathrm{Hp}$ and $\mathrm{CN}$ in our patients.

Material and methods: A total of 314 patients, aged 16-86 years, who underwent gastroscopy and colonoscopy at our department between 2015 and 2017 were evaluated retrospectively. The age, gender, endoscopy results, presence of Hp, complete blood count (CBC), vitamin $B_{12}$, folic acid, C-reactive protein (CRP), and sedimentation levels of the patients were examined.

Results: $C B C$, ferritin, vitamin $B_{12}$, and CRP measurements did not show statistical significance in terms of the presence of $\mathrm{Hp}(p>0.05)$. Folate values of Hp-positive patients were significantly lower than Hp-negative patients $(p=0.007 ; p<0.01)$. No significant relationship was detected between $\mathrm{Hp}$ and colon cancer $(p>0.05)$. Adenomatous polyps were not related to $\mathrm{Hp}$ $(p>0.05)$. Correlation between intestinal metaplasia $(I M)$ and adenomatous polyps was insignificant. There was no statistically significant difference between colon and gastric pathology results.

Conclusions: In our study, no significant relationship was noted between $\mathrm{Hp}$ and CN. A few studies have been conducted in our country, and our results are consistent with some of these studies while it is contradictory to others. Large populational multicentre studies are needed in order to identify the relationship between $\mathrm{Hp}$ and $\mathrm{CN}$.
\end{abstract}

\section{Introduction}

Helicobacter pylori $(\mathrm{Hp})$ is one of the most common infectious agents, although its incidence varies among societies. Colorectal cancer is one of the most common cancers in the world. It is of great importance to elucidate the pathogenesis and risk factors of colorecta cancer. Thus, the potential role of infectious agents was targeted for the prevention of colorectal cancer and polyp cancer spectrum [1-3]. A large number of infectious agents are being investigated in this respect. In many epidemiological studies, Hp was associated with colorectal neoplasia [4, 5].

\section{Aim \\ Our study aimed to determine whether there is a potential relationship between $\mathrm{Hp}$ and colorectal neo-}

plasia in patients who underwent simultaneous gastroscopy and colonoscopy and in whom Hp was examined in the gastric mucosa histopathologically.

\section{Material and methods}

\section{Study population}

This study was conducted retrospectively on 314 patients who were admitted to the outpatient clinic of our internal medicine department between the years of 2015 and 2017 and/or who underwent gastroscopy for Hp level during hospitalisation, who simultaneously underwent colonoscopy, and were selected in accordance with the inclusion and exclusion criteria from these patients. Our study was approved in terms of method and principle with the decision of the Ethics Committee of our hospital dated 03/05/2017 and numbered 39. 
In our study, the cases who were present in the pathology and endoscopy records of our hospital, who were in the age range of 16-86 years, who underwent gastroscopy and colonoscopy, and in whom Hp was examined were included. The age, gender, endoscopic and colonoscopic diagnoses of gastroscopy and colonoscopy, positivity or negativity of Hp, thrombocyte count, haemoglobin, mean corpuscular volume (MCV), ferritin, total iron binding capacity, vitamin $B_{12}$, folic acid, C-reactive protein (CRP), and sedimentation levels of the participating cases were examined. The cases who were detected to be positive and negative in terms of $\mathrm{Hp}$ were collected from the pathological database and randomised according to the available population. The results of both groups were compared, as well as the subgroups according to positivity and negativity of $\mathrm{Hp}$ and intestinal metaplasia were compared among each other. They were grouped as group $\mathrm{A}$ : $\mathrm{Hp}(-)$ and intestinal metaplasia (IM) (-); group B: $\mathrm{Hp} \mathrm{(+)} \mathrm{and} \mathrm{IM} \mathrm{(-);}$ group C: Hp (+) and IM (+); group D: Hp (-) and IM (+).

Adult patients aged over 16 years, in whom upper gastrointestinal (Gl) endoscopy was planned due to dyspepsia, iron deficiency anaemia, or weight loss were enrolled the study.

The exclusion criteria of the study were having gastric cancer, gastric lymphoma, and colon cancer, patients who were pregnant or breastfeeding, patients who underwent gastroduodenal surgery, history of allergic reaction to one the agents used in $\mathrm{Hp}$ eradication therapy, history of antibiotic or proton pump inhibitor therapy in the last four weeks, and those to whom $\mathrm{Hp}$ eradication was administered previously.

\section{Endoscopy and biopsy sampling}

Gastroscopy and colonoscopy were performed in all of the patients included. After recording the findings of gastroscopy and colonoscopy, a biopsy was taken from the suspected areas and stomach. If there was no visually detected polyp or if there was a suspicious lesion disrupting the mucosal integrity, the biopsy was not taken from the colon and it was named as normal colon.

\section{Statistical analysis}

The NCSS (Number Cruncher Statistical System) 2007 (Kaysville, Utah, USA) program was used for the statistical analysis. While assessing the study data, in addition to the descriptive statistical methods (mean, standard deviation, median, frequency, ratio, minimum, maximum), Student's $t$-test was used for two-group comparisons of the data with normal distribution and Mann-Whitney $U$ test was used for two-group comparisons of the data with non-normal distribution for the comparisons of quantitative values. Pearson $\chi^{2}$ test, Fisher's exact test, and Fisher Freeman Halton Test were used for the comparison of qualitative data, whereas logistic regression analysis was used to assess the effects on colon pathology. The $p$-value $<0.05$ was considered significant.

\section{Results}

The mean age of the patients was found to be 55.69 \pm 14.22 years. No statistically significant difference was found in terms of Hp incidence between the genders of the patients $(p>0.05)$. The gender distribution of the patients was $54.5 \%$ female and $45.5 \%$ male. The ratio of colon cancer was determined to be 3.5 in both $\mathrm{Hp}$-positive and -negative patients (Table I).

The thrombocyte counts, haemoglobin (HGB), MCV, ferritin, iron, total iron binding capacity (TIBC), vitamin $B_{12}$, and CRP measurements of the patients did not show statistical significance in terms of the presence of $\mathrm{Hp}(p>0.05)$. The folic acid levels of Hp-positive patients were found to be lower at a statistically significant level compared to Hp-negative ones $(p<0.01)$ (Table II).

Table I. Assessment of the presence of Helicobacter pylori $(\mathrm{Hp})$ according to demographic characteristics and colon biopsy results

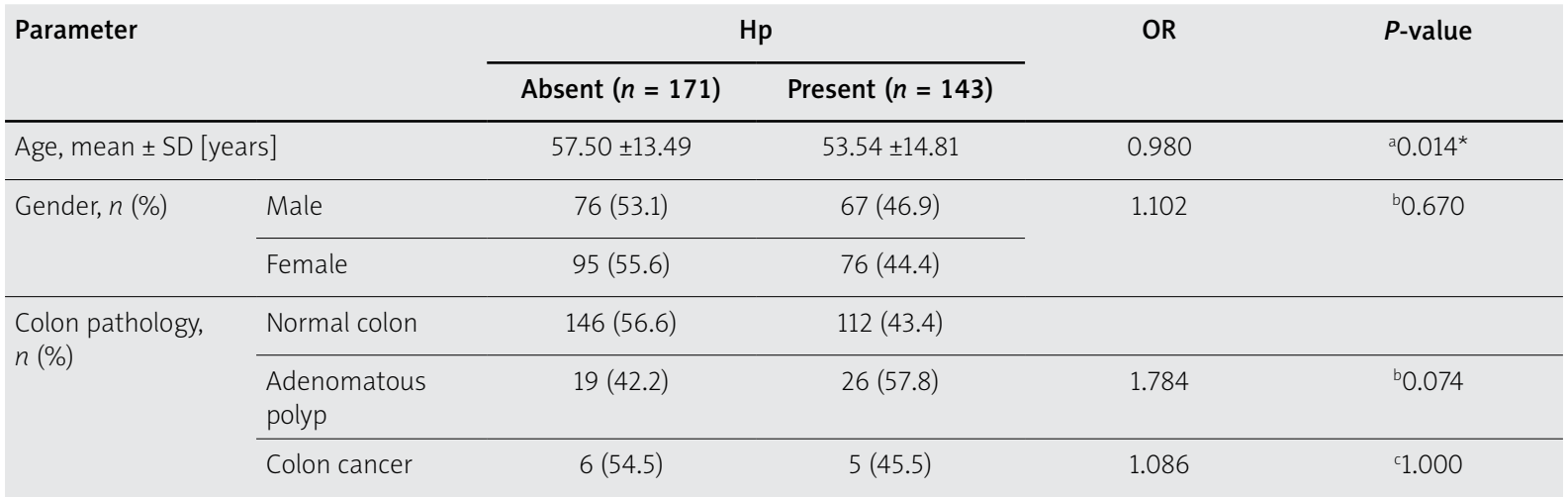

aStudent's t-test, ${ }^{b}$ Pearson's $\chi^{2}$ test, 'Fisher's Exact Test; ${ }^{*} p<0.05$. 
There was no statistically significant difference among colon pathology results in terms of gastric pathology results $(p>0.05)$ (Table III).

When we tested the groups obtained from $\mathrm{Hp}$ and IM, which have an impact on adenomatous polyps with logistic regression analysis, the model was not found to be statistically significant $(p>0.05)$ (Table IV).

\section{Discussion}

Colon cancer is an important cancer type in terms of cancer-related mortality and morbidities all over the world [6]. The available data regarding its aetiology imply that dietary fibre deficiency, nutrition with fatty and animal products, and alcohol and cigarette consumption are involved [7]. In recent years, studies have been carried out on the possibility of Hp among these factors. Sporadic forms of colorectal cancer usually arise from adenomatous polyps [8, 9]. Early diagnosis and removal of colorectal polyps led to a decrease in the incidence and mortality of colorectal cancers [10]. Recent investigations have focused on the role of infectious agents for the prevention of colorectal cancers

Table II. Assessment of laboratory results according to the presence of Helicobacter pylori $(\mathrm{Hp})$

\begin{tabular}{|c|c|c|c|c|c|}
\hline \multirow[t]{2}{*}{ Parameter } & \multicolumn{4}{|c|}{$\mathrm{Hp}$} & \multirow[t]{2}{*}{$P$-value } \\
\hline & $N$ & Absent & $N$ & Present & \\
\hline Thrombocyte count, mean \pm SD & 137 & $\begin{array}{l}278306.57 \\
\pm 96937.56 \\
\end{array}$ & 121 & $\begin{array}{l}287333.06 \\
\pm 91128.68 \\
\end{array}$ & ${ }^{\mathrm{a}} 0.443$ \\
\hline $\mathrm{HGB}$, mean $\pm \mathrm{SD}$ & 139 & $11.49 \pm 2.52$ & 121 & $11.9 \pm 2.32$ & ${ }^{\mathrm{a}} 0.170$ \\
\hline MCV, mean \pm SD & 139 & $83.91 \pm 10.76$ & 121 & $83.03 \pm 9.77$ & ${ }^{\mathrm{a}} 0.493$ \\
\hline Ferritin, mean $\pm \mathrm{SD}$ & 93 & $46.66 \pm 72.41$ & 80 & $61.08 \pm 124.97$ & ${ }^{e} 0.682$ \\
\hline Iron, mean \pm SD & 96 & $58.92 \pm 63.83$ & 71 & $60.73 \pm 66.05$ & e 0.916 \\
\hline TIBC, mean \pm SD & 92 & $351.18 \pm 100.8$ & 66 & $326.26 \pm 87.67$ & a 0.108 \\
\hline Vitamin $B_{12}$, mean $\pm S D$ & 101 & $313.46 \pm 276.23$ & 69 & $278.29 \pm 201.37$ & e 0.994 \\
\hline Folic acid, mean $\pm S D$ & 73 & $8.97 \pm 4.99$ & 44 & $7.09 \pm 2.39$ & ${ }^{\mathrm{a}} 0.007^{\star}$ \\
\hline CRP, mean \pm SD & 87 & $17.85 \pm 27.95$ & 61 & $12.34 \pm 20.83$ & ${ }^{\mathrm{e}} 0.131$ \\
\hline
\end{tabular}

aStudents t-test, ${ }^{e}$ Mann-Whitney $U$ test, ${ }^{*} p<0.05$. HGB - haemoglobin, MCV - mean corpuscular volume, TIBC-total iron binding capacity, CRP - C reactive protein.

Table III. Assessment of demographic characteristics according to gastric intestinal metaplasia (IM) results

\begin{tabular}{|c|c|c|c|c|}
\hline \multirow[t]{2}{*}{ Colon pathology } & \multicolumn{2}{|c|}{ Gastric intestinal metaplasia } & \multirow[t]{2}{*}{ OR } & \multirow[t]{2}{*}{$P$-value } \\
\hline & IM $(+)(n=46)$ & $\mathrm{IM}(-)(n=268)$ & & \\
\hline Normal colon & $36(78.3)$ & $222(82.8)$ & & \\
\hline Adenomatous polyp & $6(13.0)$ & 39 (14.6) & 0.949 & ${ }^{\mathrm{a} 0} 0.074$ \\
\hline Colon cancer & $4(8.7)$ & $7(2.6)$ & 3.524 & b1.000 \\
\hline
\end{tabular}

apearson's $\chi^{2}$ test, ${ }^{b}$ Fisher's exact test.

Table IV. Assessment of subgroups according to the presence of Helicobacter pylori $(\mathrm{Hp})$ and intestinal metaplasia (IM)

\begin{tabular}{|c|c|c|c|c|c|c|}
\hline Group & $\mathrm{Hp}$ & IM & Normal colon $(n=258)$ & Adenomatous polyp $(n=45)$ & OR & $P$-value \\
\hline A & $(-)$ & $(-)$ & $126(48.8)$ & $18(40.0)$ & 2.857 & 0.110 \\
\hline B & $(+)$ & $(-)$ & $96(37.2)$ & $21(46.7)$ & 4.375 & 0.240 \\
\hline C & $(+)$ & $(+)$ & $16(6.2)$ & $5(11.1)$ & 6.250 & 0.320 \\
\hline D & $(-)$ & $(+)$ & $20(7.8)$ & $1(2.2)$ & - & 0.161 \\
\hline
\end{tabular}

Logistic regression analysis. 
and the polyp-cancer spectrum [11-13]. Many epidemiological studies associated $\mathrm{Hp}$ infection with colorectal neoplasia; among colorectal cancer patients or patients with colon polyps it was reported to be associated with a high prevalence of Hp seropositivity [14-16], the presence of bacterial bio products, and their trophic effect on colon mucosa $[17,18]$, while some were found to be irrelevant [19-21]. Furthermore, several studies concern colon cancer and/or polyps with the presence of $\mathrm{Hp}$ in the stomach [22] or colon [22, 23].

We retrospectively evaluated the relationship between colonic neoplasia and $\mathrm{Hp}$ in our study. The mean age of the patients was found to be $55.69 \pm 14.22$ years, which is similar to the literature. In the study by Qing et al. including 233 patients in 2012, the ages of the patients were determined to vary between 16 and 89 years, and the mean age of the patients was found to be 56.85 \pm 12.38 years [24]. The gender distributions of the patients in our study were $54.5 \%$ female and $45.5 \%$ male.

We found folic acid deficiency in our Hp-positive patients. Numerous studies demonstrated that $\mathrm{Hp}$ infection was associated with the deficiency of copper, vitamin $B_{12}$, folic acid, and vitamin $A, C$, and $E[25,26]$. These deficiencies originate from the anorexia caused by dyspeptic symptoms and malabsorption secondary to intestinal bacterial infections, which is the resultant of hypo-achlorhydria in the presence of Hp [27]. Gulsen et al. found a statistically significant increase in the serum $B_{12}$ and folate levels after $\mathrm{Hp}$ eradication [28].

In the meta-analysis including 11 studies conducted by Zumkeller et al. in 2006, a possible small increase in risk of colorectal cancer because of $\mathrm{Hp}$ infection was suggested [29]. In the meta-analysis conducted by Yashuang et al. published in 2008 and in two more Japanese studies published in 2005 a total of 13 studies were included, and the relationship of $\mathrm{Hp}$ with colorectal cancer was calculated [30]. The status of $\mathrm{Hp}$ in 11 studies included in this analysis was determined by IgG measurement and calculated only when these were included. In both meta-analyses, it was emphasised that the differences in the diagnostic methods of the studies and ethnicity, as well as the heterogeneity of patient populations, might have affected the results. In a recently published study in which $96 \mathrm{Hp}$-positive and $96 \mathrm{Hp}$-negative patients with abnormal colonoscopy findings (adenomatous polyp, colon cancer, hyperplastic polyp) were compared, the colon cancer ratio was found to be $2 \%$ in the $\mathrm{Hp}$-positive group and $6 \%$ in the $\mathrm{Hp}$-negative group. The difference between groups was not found to be statistically significant [31]. In the study by Kos et al. from our country, no significant difference was detected in terms of $\mathrm{Hp}$ seropositivity in the colon cancer group compared to the control group. Hp can be affected by factors such as race and geographical region [30]. Another study from Turkey by Soylu et al. obtained results supporting the negative correlation [32]. We found the rate of colon cancer as 3.5\% in both $\mathrm{Hp}$-positive and -negative patients.

Although a significant relationship was not revealed between $\mathrm{Hp}$ and colorectal neoplasia in our study, early reports suggest that $\mathrm{Hp}$ infection and colorectal neoplasia (especially colorectal adenomas) might be associated with each other [33]. Several previous studies demonstrated that there was a positive correlation between H. pylori infection and colorectal neoplasia in different societies such as Afro-Americans [34], German [35], and Israeli [36] populations. However, Strofilas et al. found that there was no difference between a colorectal cancer group and control group in terms of anti-Hp antibodies [37]. Additionally, a similar lack of relationship between $\mathrm{Hp}$ and colorectal adenoma was reported in the Hispanic population in the USA [38]. Therefore, it was considered that the relationship between $\mathrm{Hp}$ and colorectal neoplasia was associated with ethnicity, making ethnic-based data analysis important [39].

There are many studies investigating the relationship between $\mathrm{Hp}$ and colorectal neoplasia, with contradictory results. Our study indicated that $\mathrm{Hp}$ was not associated with colorectal adenomas. This result may be attributed to the racial differences or it might have been caused by the variable prevalence of $\mathrm{Hp}$ infection and $I M$ in different regions. The differences among studies may also be related to the following: bias in patient selection, using different tests to diagnose $\mathrm{Hp}$, differences in the history of previous $\mathrm{Hp}$ eradication treatment or colorectal polyp removal, or the presence of other uncontrollable confounding factors.

Obtaining contradictory results about the relationship between $\mathrm{Hp}$ and colorectal neoplasia has further increased the interest in this issue. Two cross-sectional studies using health check-up databases in Korea and Taiwan showed that Hp infection was significantly associated with increased risk of colorectal adenomas. In a case-control study by Inoue et al. in 2011 in which 478 asymptomatic Japanese factory workers were examined, Hp infection was identified as a risk factor for colorectal adenoma [40]. Also, in a case control study on a population in Germany, Hp immunoglobulin (Ig) $\mathrm{G}$ and cytotoxin-associated gene A protein (CagA) were used, and a positive relationship was suggested between $\mathrm{Hp}$ and colorectal cancer [41].

Several interpretations were made to explain the mechanism of increased risk of colorectal adenoma with $\mathrm{Hp}$ infection. According to the most commonly described pathogenesis, Hp infection causes hypergastrinaemia. This contributes to colorectal cancer devel- 
opment by making a trophic effect on the epithelial cell growth and proliferation [42]. In fact, gastrin and cholecystokinin B/gastrin receptors appear early in human colon polyps via the activation in the adenoma-carcinoma spectrum [43]. Many epidemiological studies confirmed the association between hypergastrinaemia and increased risk of colorectal neoplasia [44, 45]; however, the findings are controversial $[46,47]$. Hp infection, aging, alcohol consumption, smoking, excessive salt intake, and bile reflux are considered as factors associated with IM [48, 49].

Ye et al. retrospectively reviewed 1641 patients aged $\geq 40$ years in China in 2016. Histopathological results were obtained from the gastric and colorectal biopsies. In that study, Hp infection was found to be significantly associated with the increased risk of colorectal adenomas. The results are consistent with those of previous studies showing a positive correlation between $\mathrm{Hp}$ infection and colorectal adenomas [50, 51]. In addition, the cases with IM were observed to have increased risk of colorectal adenoma. A broad-based case-control study with 156,000 enrolled patients showed a positive correlation between IM and colorectal adenomas, but the study did not include the analysis of the association between $H$. pylori-associated IM and colorectal adenomas [52]. Also, a recent study showed that the individuals with IM were more likely to have high-grade intraepithelial adenomas [53]. In our literature review, we noted that there has been no study analysing the relationship between $H$. pylori-associated IM and colorectal neoplasia in our country. In this study, we did not find a significant relationship between intestinal metaplasia and colon cancer. Additionally, we performed a subgroup analysis in which groups were created based on the presence of $\mathrm{Hp}$ and IM. In our study, we observed that IM accompanied by $\mathrm{Hp}$ did not increase the risk of colon neoplasia. While a significant relationship was detected in other studies, the lack of a significant relationship in our study may be due to the limited number of patients and the broader age range. The cases in our study were older than 16 years, while the other cases were selected as over 40 years of age. Prolonged Hp infection may be important for the development of colorectal adenoma because IM is usually a chronic sequela of $\mathrm{Hp}$.

The IM occurs first at the junction of corpus-antrum, then spreads to both corpus and antrum, and replaces normal gastric cells [54]. Decreased gastric acid secretion triggered by IM may cause hypergastrinaemia. Also, hypochlorhydria interferes with protein absorption, leading to bacterial overgrowth, thereby increasing in the metabolites and non-absorbed nutrients, which contributes to colonic diseases and colorectal carcinogen- esis [55]. For this reason, $H$. pylori-associated IM may aggravate colorectal carcinogenesis.

Our study has some limitations. First of all, we did not measure the gastrin level, which is the key mechanism in the development of colorectal neoplasia secondary to $\mathrm{Hp}$. Secondly, multiple biopsies were taken from very few patients, and this decreased the possibility of detecting gastric intestinal metaplasia. Thirdly, this was a single-centre study with a small sample size. Multicentre studies with large sample sizes should be carried out in our country and at the international level.

\section{Conclusions}

Our study revealed that there was no relationship between $\mathrm{Hp}$ and colorectal neoplasia. However, the studies with larger sample sizes indicate that there might be a relationship. Also, the differences among studies indicate that there might be regional differences as well. Considering that colorectal cancers are a significant cause of mortality and morbidity, this subject should be explored in depth in our country and throughout the world, through multicentre studies with large sample sizes. Hp has been proven to be involved in the aetiology of many diseases. When $\mathrm{Hp}$ is detected, the patient should be evaluated for eradication, by taking the benefit-harm balance into account.

\section{Conflict of interest}

Authors declare no conflict of interest.

\section{References}

1. Burnett-Hartman AN, Newcomb PA, Potter JD. Infectious agents and colorectal cancer: a review of Helicobacter pylori, Streptococcus bovis, JC virus, and human papilloma virus. Cancer Epidemiol Biomarkers Prev 2008; 17: 2970-9.

2. Meira LB, Bugni JM, Green SL, et al. DNA damage induced by chronic inflammation contributes to colon carcinogenesis in mice. J Clin Invest 2008; 118: 2516-25.

3. Dejea C, Wick E, Sears CL. Bacterial oncogenesis in the colon. Future Microbiol 2013; 8: 445-60.

4. Fujimori S, Kishida T, Kobayashi T, et al. Helicobacter pylori infection increases the risk of colorectal adenoma and adenocarcinoma, especially in women. J Gastroenterol 2005; 40: 887-93.

5. Zhang Y, Gao C, Zhai JH. Meta-analysis on the relationship between colorectal cancer and Helicobacter pylori infection Zhonghua Liu Xing Bing Xue Za Zhi 2009; 30: 73-7.

6. Cummings LC, Cooper GS. Colorectal cancer screening: update for 2011. Semin Oncol 2011; 38: 483-9.

7. Gustin DM, Brenner DE. Chemoprevention of colon cancer: current status and future prospects. Cancer Metastasis Rev 2002; 21: 323-48.

8. Hawkins NJ, Ward RL. Sporadic colorectal cancers with microsatellite instability and their possible origin in hyperplastic 
polyps and serrated adenomas. J Natl Cancer Inst 2001; 93 1307-13.

9. Jass JR. Hyperplastic-like polyps as precursors of microsatellite-unstable colorectal cancer. Am J Clin Pathol 2003; 119: 773-75.

10. Kahi CJ, Imperiale TF, Juliar BE, et al. Effect of screening colonoscopy on colorectal cancer incidence and mortality. Clin Gastroenterol Hepatol 2009; 7: 770-5.

11. Burnett-Hartman AN, Newcomb PA, Potter JD. Infectious agents and colorectal cancer: a review of Helicobacter pylori, Streptococcus bovis, JC virus, and human papillomavirus. Cancer Epidemiol Biomarkers Prev 2008; 17: 2970-9.

12. Meira LB, Bugni JM, Green SL, et al. DNA damage induced by chronic inflammation contributes to colon carcinogenesis in mice. J Clin Invest 2008; 118: 2516-25.

13. Dejea C, Wick E, Sears CL. Bacterial oncogenesis in the coIon. Future Microbiol 2013; 8: 445-60.

14. Fujimori S, Kishida T, Kobayashi T, et al. Helicobacter pylori infection increases the risk of colorectal adenoma and adenocarcinoma, especially in women. J Gastroenterol 2005; 40: 887-93.

15. Zhao YS, Wang F, Chang D, et al. Meta-analysis of different test indicators: Helicobacter pylori infection and the risk of colorectal cancer. Int J Colorectal Dis 2008; 23: 875-82.

16. Zumkeller N, Brenner H, Chang-Claude J, et al. Helicobacter pylori infection, interleukin-1 gene polymorphisms and the risk of colorectal cancer: evidence from a case-control study in Germany. Eur J Cancer 2007; 43: 1283-9.

17. D'Onghia V, Leoncini R, Carli R, et al. Circulating gastrin and ghrelin levels in patients with colorectal cancer: correlation with tumour stage, Helicobacter pylori infection and BMI. Biomed Pharmacother 2007; 61: 137-41.

18. Polymeros D, Triantafyllou K, Spiliadi C, et al. Hypergastrinemia is associated with increased risk of distal colon adenomas. Digestion 2006; 74: 42-6.

19. Limburg PJ, Stolzenberg-Solomon RZ, Colbert LH, et al. Helicobacter pylori seropositivity and colorectal cancer risk: a prospective study of male smokers. Cancer Epidemiol Biomarkers Prev 2002; 11: 1095-9.

20. Robertson DJ, Sandler RS, Ahnen DJ, et al. Gastrin, Helicobacter pylori, and colorectal adenomas. Clin Gastroenterol Hepatol 2009; 7: 163-7.

21. Bae RC, Jeon SW, Cho HJ, et al. Gastric dysplasia may be an independent risk factor of an advanced colorectal neoplasm. World J Gastroenterol 2009; 15: 5722-6.

22. Grahn N, Hmani-Aifa M, Fransen K, et al. Molecular identification of Helicobacter DNA present in human colorectal adenocarcinomas by $16 \mathrm{~S}$ rDNA PCR amplification and pyrosequencing analysis. J Med Microbiol 2005; 54: 1031-5.

23. Soylu A, Ozkara S, Alis H, et al. Immunohistochemical testing for Helicobacter pylori existence in neoplasms of the colon. BMC Gastroenterol 2008; 8: 35.

24. Qing Y, Wang M, Lin YM, et al. Correlation between Helicobacter pylori-associated gastric diseases and colorectal neoplasia. World J Gastroenterol 2016; 22: 4576-84.

25. Salgueiro J, Zubillaga M, Goldman C, et al. Review article: is there a link between micronutrient malnutrition and Helicobacter pylori infection? Aliment Pharmacol Ther 2004; 20 1029-34.
26. Solnick JV, Franceschi F, Roccarina D, et al. Extragastric manifestations of Helicobacter pylori infection-other Helicobacter species. Helicobacter 2006; 11: 46-51.

27. Ozturk N, Kurt N, Ozgeris FB, et al. Serum zinc, copper, magnesium and selenium levels in children with Helicobacter pylori Infection. Eurasian J Med 2015; 47: 126-9.

28. Gulsen M, Battal A, Uygurer C, et al. Helicobacter pylori and cobalamine deficiency. Turk J Gastroenterol 1998; 2: 126-32.

29. Zumkeller N, Brenner H, Zwahlen M, et al. Helicobacter pylori infection and colorectal cancer risk: a meta-analysis. Helicobacter 2006; 11: 75-80.

30. Zhao YS, Wang F, Chang D, et al. Meta-analysis of different test indicators: Helicobacter pylori infection and the risk of colorectal cancer. Int J Colorectal Dis 2008; 23: 875-82.

31. Abbass K, Gul W, Beck G, et al. Association of Helicobacter pylori infection with the development of colorectal polyps and colorectal carcinoma. South Med J 2011; 104: 473-6.

32. Soylu A, Ozkara S, Alis H, et al. Immunohistochemical testing for Helicobacter pylori existence in neoplasms of the colon. BMC Gastroenterol 2008; 8: 35.

33. Meucci G, Tatarella M, Vecchi M, et al. High prevalence of Helicobacter pylori infection in patients with colonic adenomas and carcinomas. J Clin Gastroenterol 1997; 25: 605-7.

34. Brim H, Zahaf M, Laiyemo AO, et al. Gastric Helicobacter pylori infection associates with an increased risk of colorectal polyps in African Americans. BMC Cancer 2014; 14: 296.

35. Selgrad M, Bornschein J, Kandulski A, et al. Helicobacter pylori but not gastrin is associated with the development of colonic neoplasms. Int J Cancer 2014; 135: 1127-31.

36. Shmuely H, Melzer E, Braverman M, et al. Helicobacter pylori infection is associated with advanced colorectal neoplasia. Scand I Gastroenterol 2014; 49: 35-42.

37. Strofilas A, Lagoudianakis EE, Seretis C, et al. Association of Helicobacter pylori infection and colon cancer. J Clin Med Res 2012; 4: 172-6.

38. Patel S, Lipka S, Shen H, et al. The association of H. pylori and colorectal adenoma: does it exist in the US Hispanic population? J Gastrointest Oncol 2014; 5: 463-8.

39. Venerito $M$, Vasapolli R, Rokkas T, et al. Helicobacter pylori and gastrointestinal malignancies. Helicobacter 2015; 20: 36-9.

40. Inoue I, Mukoubayashi C, Yoshimura N, et al. Elevated risk of colorectal adenoma with Helicobacter pylori-related chronic gastritis: a population-based case-control study. Int J Cancer 2011; 129: 2704-11.

41. Konturek SJ, Konturek PC, Hartwich A, et al. Helicobacter pylori infection and gastrin and cyclooxygenase expression in gastric and colorectal malignancies. Regul Pept 2000; 93: 13-9.

42. Renga M, Brandi G, Paganelli GM, et al. Rectal cell proliferation and colon cancer risk in patients with hypergastrinemia. Gut 1997; 41: 330-2.

43. Smith AM, Watson SA. Gastrin and gastrin receptor activation: an early event in the adenoma-carcinoma sequence. Gut 2000; 47: 820-4.

44. Polymeros D, Triantafyllou K, Spiliadi C, et al. Hypergastrinemia is associated with increased risk of distal colon adenomas. Digestion 2006; 74: 42-6.

45. Thorburn CM, Friedman GD, Dickinson CJ, et al. Gastrin and colorectal cancer: a prospective study. Gastroenterology 1998; 115: 275-80. 
46. Selgrad M, Bornschein J, Kandulski A, et al. Helicobacter pylori but not gastrin is associated with the development of colonic neoplasms. Int J Cancer 2014; 135: 1127-31.

47. Kikendall JW, Glass AR, Sobin LH, et al. Serum gastrin is not higher in subjects with colonic neoplasia. Am J Gastroenterol 1992; 87: 1394-7.

48. Robertson DJ, Sandler RS, Ahnen DJ, et al. Gastrin, Helicobacter pylori, and colorectal adenomas. Clin Gastroenterol Hepatol 2009; 7: 163-7.

49. Leung WK, Lin SR, Ching JY, et al. Factors predicting progression of gastric intestinal metaplasia: results of a randomised trial on Helicobacter pylori eradication. Gut 2004; 53: 1244-9.

50. Brim H, Zahaf M, Laiyemo AO, et al. Gastric Helicobacter pylori infection associates with an increased risk of colorectal polyps in African Americans. BMC Cancer 2014; 14: 296.

51. Inoue I, Mukoubayashi C, Yoshimura N, et al. Elevated risk of colorectal adenoma with Helicobacter pylori-related chronic gastritis: a population-basedcase-control study. Int J Cancer 2011; 129: 2704-11.

52. Sonnenberg A, Genta RM. Helicobacter pylori is a risk factor for colonic neoplasms. Am J Gastroenterol 2013; 108: 208-15.

53. Qing Y, Wang M, Lin YM, et al. Correlation between Helicobacter pylori-associated gastric diseases and colorectal neoplasia. World J Gastroenterol 2016; 22: 4576-84.

54. Kneller RW, You WC, Chang YS, et al. Cigarette smoking and other risk factors for progression of precancerous stomach lesions. J Natl Cancer Inst 1992; 84: 1261-6.

55. Correa P, Piazuelo MB, Wilson KT. Pathology of gastric intestinal metaplasia: clinical implications. Am J Gastroenterol 2010; 105: 493-8.

Received: 19.10 .2018

Accepted: 21.11 .2018 